\title{
HIDROQUÍMICA ELEMENTAR E DOS ISÓTOPOS DE URÂNIO EM ÁGUAS SUBTERRÂNEAS DA FORMAÇÃO ALTER DO CHÃO, MANAUS (AM)
}

\author{
MÁRCIO LUIZ DA SILVA ${ }^{1} \&$ DANIEL MARCOS BONOTTO ${ }^{2}$
}

\begin{abstract}
Resumo O abastecimento de água no município de Manaus, Estado do Amazonas, Brasil, é realizado por empresa particular, através da captação das águas do rio Negro e por poços tubulares. Este trabalho tem por objetivo investigar tanto a hidroquímica quanto o comportamento geoquímico dos isótopos de urânio ${ }^{238} \mathrm{U}$ e ${ }^{234} \mathrm{U}$ nas águas subterrâneas de Manaus, de maneira a proceder à caracterização de contaminantes ou poluentes que possam estar afetando a qualidade dos recursos hídricos em sub-superfície, bem como avaliar a potencialidade do uso dos isótopos naturais de urânio como traçadores hidrológicos no aqüífero estudado. No que diz respeito aos isótopos de urânio, verifica-se que foram determinados valores de razão de atividade ${ }^{234} U{ }^{238} U$ entre 1,2 e 4,4 e de concentração de urânio entre 0,003 e $1,1 \mu \mathrm{g} . \mathrm{L}^{-1}(\mathrm{ppb})$. Esses resultados e os determinados para outros parâmetros analisados permitiram identificar que as águas estudadas são adequadas para o consumo humano e também classificar o sistema hídrico como redutor ácido, com circulação das águas por estratos contendo minerais com baixas concentrações de urânio.
\end{abstract}

Palavras-chaves: hidroquímica de águas subterrâneas, abastecimento público na Amazônia, isótopos de urânio em águas subterrâneas.

\begin{abstract}
ELEMENTAL HYDROCHEMISTRY AND HYDROGEOCHEMISTRY OF THE URANIUM ISOTOPES IN ALTER DO CHÃO FORMATION, MANAUS (AMAZON - BRAZIL). The water exploitation at Manaus city, Amazonas State, Brazil, takes place from Negro River and tubular wells, being performed by a private company. This paper evaluates the hydrochemistry and geochemical behavior of uranium isotopes $\left({ }^{238} \mathrm{U}\right.$ and $\left.{ }^{234} \mathrm{U}\right)$ in groundwaters from Manaus city, with the aim to characterize the contaminants or pollutants that possibly are affecting the quality of the underground hydrological resources, as well as to evaluate the potential use of the natural U-isotopes as hydrological tracers in the aquifer studied. The U-isotopes analysis allowed to determine ${ }^{234} \mathrm{U}{ }^{238} \mathrm{U}$ activity ratios of 1.2-4.4, and dissolved uranium concentration of 0.003-1.1 $\mu \mathrm{g} . \mathrm{L}^{-1}$ (ppb). These results and those concerning the others parameters indicated that the waters are appropriate for human consumption, permitting to classify the hydrological system as acid-reducing, and to say that the waters leach minerals in strata containing low U content.
\end{abstract}

Keywords: groundwater hydrochemistry, public water-supply in Amazon, uranium isotopes in groundwaters.

INTRODUÇÃO Ao infiltrar no solo, a água vai adquirindo características químicas que fornecem informações do meio pelo qual circula. A radioatividade natural das águas é decorrente da presença de elementos radioativos existentes nas rochas e solos, que são liberados durante a infiltração da água, face às reações que ocorrem com os minerais com os quais interage. Há vários anos, pesquisas hidrológicas têm sido realizadas enfocando os isótopos naturais de urânio ${ }^{238} \mathrm{U}$ e ${ }^{234} \mathrm{U}$, os quais têm sido empregados para diversas finalidades.

A utilização de água subterrânea para o abastecimento público e industrial, vem crescendo em todo o globo. Na Amazônia, tem-se observado crescente perspectiva de explotação dessa água, por apresentar vantagens práticas e econômicas quanto à sua captação, além de dispensar tratamentos, por ser normalmente de excelente qualidade.

O grupo francês Suez adquiriu a Manaus Saneamento que passou a se chamar Águas do Amazonas S.A. a partir de $11 / 08 / 2000$, com contrato de concessão de 30 anos pelos serviços de água e esgoto na cidade de Manaus, sendo esta a primeira privatização do setor de saneamento de uma capital brasileira. O abastecimento de água no município de Manaus tem sido efetuado por intermédio de poços tubulares e de captação do rio Negro. Os primeiros poços exploratórios de aqüíferos na região amazônica começaram a serem perfurados a partir de 1976 (Souza, 1994), quando também foram realizados alguns trabalhos relacionados à hidroquímica de águas superficiais e subterrâneas, porém, sem alusão à presença dos isótopos naturais de urânio ${ }^{238} \mathrm{U} \mathrm{e}^{234} \mathrm{U}$. Um estudo conduzido por Silva (2001) indicou que, na cidade de Manaus, a água subterrânea é de ex- celente qualidade para o consumo humano e industrial, exceto a que provém de poços rasos (até 50 metros de profundidade) perfurados na zona urbana, os quais, geralmente, têm apresentado contaminação bacteriológica.

O presente trabalho investiga a hidroquímica elementar e o comportamento geoquímico dos isótopos de urânio ${ }^{238} \mathrm{U}$ e ${ }^{234} \mathrm{U}$ nas águas subterrâneas da cidade de Manaus, de maneira a identificar possíveis contaminantes ou poluentes que podem estar afetando a qualidade dos recursos hídricos em subsuperfície, bem como avaliar a potencialidade do uso dos isótopos naturais de urânio como traçadores hidrológicos no aqüífero estudado.

ASPECTOS GERAIS DA ÁREA DE ESTUDO A área estimada da Bacia Amazônica corresponde a 6,3 milhões de $\mathrm{km}^{2}$. Essa região é limitada a Oeste pela Cordilheira dos Andes, ao Norte pelo Planalto das Guianas, ao Sul pelo Planalto Central e a Leste pelo Oceano Atlântico, para onde toda a água captada na bacia escoa. A área da Amazônia Legal no Brasil é de 5.032.925 $\mathrm{km}^{2}$, compreendidos pelos estados do Pará, Amazonas, Rondônia, Roraima, Acre e Amapá e parte dos estados do Tocantins, Mato Grosso e Maranhão. Oito nações compartilham a região Amazônica e 60\% do território brasileiro estão nessa área, com apenas 7,6\% da população do país (IBGE, 2002).

De acordo com Petri \& Fúlfaro (1988), a Bacia Sedimentar do Amazonas possui aproximadamente $200 \mathrm{~km}$ de largura, de ambos os lados do rio Amazonas, compreendendo, em sua quase totalidade, mais de 4 milhões de $\mathrm{km}^{2}$ da região. É caracterizada pela ocorrência de rochas sedimentares do Proterozóico ao Quaternário, sendo a planície levemente ondulada, à exceção do

1 - Coordenação de Pesquisas - Instituto Nacional de Pesquisas da Amazônia - COPE - INPA - Av. André Araújo, 2936 - Petrópolis - CEP 69083-000 - Manaus (AM) - Fone (092) 36433153 - e-mail: marciols@inpa.gov.br

2 - Departamento de Petrologia e Metalogenia - Instituto de Geociências e Ciências Exatas - UNESP - Av. 24-A, 1515 - Bela Vista - CEP 13506-900 - Rio Claro (SP) - Fone (019) 35262825 - FAX (019) 35340122 - e-mail: dbonotto@rc.unesp.br 
sudeste da região (sul do Pará, Goiás e Maranhão) e o seu extremo norte (Roraima), que apresentam relevo mais acidentado.

$\mathrm{O}$ clima da Amazônia é quente e úmido. A temperatura média é em torno de $33^{\circ} \mathrm{C}$ (setembro), chegando a $28^{\circ} \mathrm{C}$ na estação seca e $26^{\circ} \mathrm{C}$ durante as estações chuvosas. A precipitação pluviométrica anual é de 1800 a $3500 \mathrm{~mm}$ e a umidade do ar é alta, em torno de $88 \%$ no período chuvoso e $77 \%$ no seco. Os meses com maior e menor intensidade pluviométrica são, respectivamente, de novembro a abril e de junho a outubro (Prance \& Lovejoy, 1985; Santos \& Ribeiro, 1988).

A explicação acerca do regime dos rios amazônicos está relacionada com o próprio regime das chuvas na bacia e no comportamento da circulação geral atmosférica, dentro da zona intertropical sul-americana (IBGE, 2002).

Em decorrência do baixo gradiente hidráulico do rio Amazonas e seus afluentes, os detritos quaternários foram depositados sob a forma de diques, cujos flancos externos passam, suavemente, às extensas várzeas. Esses depósitos aluvionários recentes chegam a formar ilhas nas calhas dos grandes rios (Lourenço et al., 1978).

A cidade de Manaus situa-se na zona fisiográfica do Médio Amazonas, localiza-se a $03^{\circ} 08^{\prime} \mathrm{S}$ e $60^{\circ} 00^{\prime} \mathrm{W}$ (Figura 1) e abrange uma área de $11.408 \mathrm{~km}^{2}$. A população do município no ano de 2000 correspondia a 1.403.796 habitantes (IBGE, 2002), estando a grande maioria concentrada na área urbana, como conseqüência do êxodo rural que se iniciou a partir da implantação da Zona Franca de Manaus, no final da década de 1960. A área de estudo está situada sobre os sedimentos continentais da Formação Alter do Chão, oriundos da deposição de sedimentos continentais em ambientes aquosos, predominantemente lacustres e fluviais. Possivelmente foi Kistler, em 1954, o primeiro a empregar o termo Formação Alter do Chão para esses sedimentos que, em 1975, Daemon datou como sendo do Cretáceo Inferior (Caputo et al., 1972; Petri \& Fúlfaro, 1988).

A Formação Alter do Chão situa-se numa planície de dissecação que vem sofrendo movimentos positivos, desde o início do Terciário. É uma formação constituída por sedimentos vermelhos (espessura máxima de $1250 \mathrm{~m}$ ) compostos por: argilas (cor vermelha mosqueada, cinza-esbranquiçada, brancaavermelhada) plásticas, maciças e micáceas, às vezes finamente laminadas com filmes de areia, com predominância de minerais do grupo da caolinita associada à gibbsita (traços); feldspatos, quartzo e ilita (raramente); argilitos (com lentes de areia, pouco consolidados e cor vermelha, creme, branca e roxa); siltitos e arenitos (finos a médios, geralmente com estratificação cruzada e intercalações argilosas, micáceos, ferruginosos, maciços e bioturbados); conglomerados (com seixos de quartzo), pobres em fósseis e recobertos discordantemente, em parte, por sedimentos terciários ou diretamente por sedimentos quaternários (Petri \& Fúlfaro, 1988). A Formação Alter do Chão que, sob Manaus, tem uma espessura máxima de $205 \mathrm{~m}$ e uma superfície aflorante de $437.500 \mathrm{~km}^{2}$, extrapola a área municipal (Souza, 1994).

A área de estudo é plana, em seu aspecto geral, estando inserida no Planalto Dissecado Rio Trombetas-Negro, o qual foi definido por Barbosa et al. (1978) como um relevo de interflúvios tabulares e colinas com topos com extensão entre 250 a 750 m, separados por vales abertos e de fraco grau de aprofundamento. $\mathrm{Na}$ cidade de Manaus, o relevo apresenta platôs escalonados de altitudes variando de 25 a $125 \mathrm{~m}$.

Os sistemas de aqüíferos na Bacia Sedimentar do Amazonas têm um volume de água igual a $32.500 \mathrm{~km}^{3}$ e poços com intervalo de vazão de 10 a $400 \mathrm{~m}^{3} / \mathrm{h}$ (Rebouças, 1997). No Brasil são escassas as informações sobre as demandas dos principais usos da água, tendo-se somente informações difusas ou estimativas a partir de taxas de consumo para determinadas atividades. De acordo com dados do IBGE (2002), há no Brasil uma demanda diária de água distribuída de $43.999 .678 \mathrm{~m}^{3}$, sendo
40.843.004 $\mathrm{m}^{3}$ com tratamento diversificado. Na região norte, a demanda de água distribuída com tratamento representa apenas $5,61 \mathrm{~m}^{3} / \mathrm{dia}(4,08 \%)$.

Para o Estado do Amazonas, a demanda chegou a 896.185 $\mathrm{m}^{3} /$ dia, sendo que $67,76 \%$ não recebe tratamento e $2,76 \%$ recebe tratamento por simples cloração (IBGE, 2002). Dessa forma, em muitas cidades do estado do Amazonas, a distribuição da água captada por poços tubulares ou água fluvial é efetuada diretamente para a população por rede de distribuição, sem receber nenhum tratamento por parte dos órgãos responsáveis.

A organização microscópica de solos investigados por Chavel (1982) em dois perfis na região de Manaus (2 e 2,6 m de profundidade) evidencia dois sistemas de porosidade diferentes: a) conjunto de criptovazios $(<0,1 \mu \mathrm{m})$ que asseguram a retenção e a circulação muito lenta da água, conservação da caolinita e dos cátions; b) rede de mesovazios (35 a $75 \mu \mathrm{m}$ ) comunicantes, devido à atividade biológica, responsáveis pela drenagem rápida no sistema e sedes de uma desionização e dessilicificação intensa. A proximidade dos rebordos do platô e as possibilidades de drenagem lateral rápida se intensificam à medida que aumenta a declividade do terreno, permitindo a exportação do silício em solução e a concentração relativa do alumínio e do ferro (Chavel, 1982).

MATERIAL E MÉTODOS As coletas de amostras de águas subterrâneas para o desenvolvimento deste trabalho foram realizadas no período de seca regional (dezembro) em 15 poços perfurados pela CPRM-AM e distribuídos por todo o perímetro urbano da cidade de Manaus. A seleção dos poços foi feita em virtude de sua localização de fácil acesso e condições apropriadas de operação (Figura 1). No campo, as amostras foram coletadas de cada poço através de seu bombeamento e, para se evitar contaminação pela tubulação, manteve-se cada um em funcionamento por 30 minutos antes de se efetuar a amostragem. Coletou-se, inicialmente, para cada amostra, um volume adicional de $5 \mathrm{~L}$ de água para a aferição da temperatura com um termômetro de precisão de leitura de $0,1^{\circ} \mathrm{C}$. A coleta de amostras para as análises hidroquímicas foi realizada em duplicata, utilizando-se de frascos de polietileno de $2 \mathrm{~L}$. Para a análise do teor de urânio dissolvido e razão de atividade ${ }^{234} \mathrm{U} /{ }^{238} \mathrm{U}$, as amostras foram coletadas em frascos de polietileno com capacidade para $20 \mathrm{~L}$, pois, torna-se necessário o tratamento químico de um grande volume de amostra, caso a concentração do elemento seja baixa. Todos os frascos novos e limpos foram previamente lavados, enxaguados várias vezes com a própria água a ser amostrada, cheios até a boca, identificados com etiquetas numeradas e em caderneta de campo. As amostras foram cuidadosamente manuseadas para evitar contaminação e, após a coleta, foram imediatamente conduzidas ao Instituto Nacional de Pesquisas da Amazônia (INPA) para serem aferidos o pH, o potencial de óxi-redução (Eh), a condutividade elétrica, o ferro total, o $\mathrm{Fe}^{3+} \mathrm{e}$ os principais cátions e ânions dissolvidos.

$\mathrm{O} \mathrm{pH}$ e a condutividade elétrica foram aferidos com equipamento digital da marca WTW, modelo LF 191. Para a determinação do Eh recorreu-se ao analisador digital da Analion modelo IA 601, ao qual foi acoplado um eletrodo metálico de platina combinado (Analion, modelo 674), previamente calibrado com solução de Zobell, conforme procedimento descrito por Bonotto (1996). O cálcio, o magnésio e a dureza foram quantificados por complexometria com EDTA (Golterman et al., 1978), o sódio e o potássio por fotometria de chama, o ferro total e o $\mathrm{Fe}^{3+}$ por metodologia descrita em APHA (1985), a alcalinidade por potenciometria (Golterman et al., 1978), o cloreto por titulometria (Golterman et al., 1978), o nitrato por redução a nitrito (Strickland \& Parsons, 1968), o sulfato por espectrofotometria e o amônio pelo método de Nessler (Strickland \& Parsons, 1968). 
Para as análises de urânio, adicionou-se $\mathrm{HCl} 8 \mathrm{M}$ a cada amostra para evitar a precipitação de ferro no recipiente, e, então, $100 \mu \mathrm{L}$ do traçador ${ }^{232} \mathrm{U}^{228} \mathrm{Th}$ (atividade de 3,39 dpm), agitando-se vigorosamente a amostra para dissolução completa dos radionuclídeos adicionados. Depois, acrescentou-se $1 \mathrm{~mL}$ de cloreto férrico e, para induzir a floculação do material, elevou-se o pH da amostra para a faixa de 8-10, pela adição de hidróxido de amônio; nesse $\mathrm{pH}$ ocorre a precipitação de hidróxido

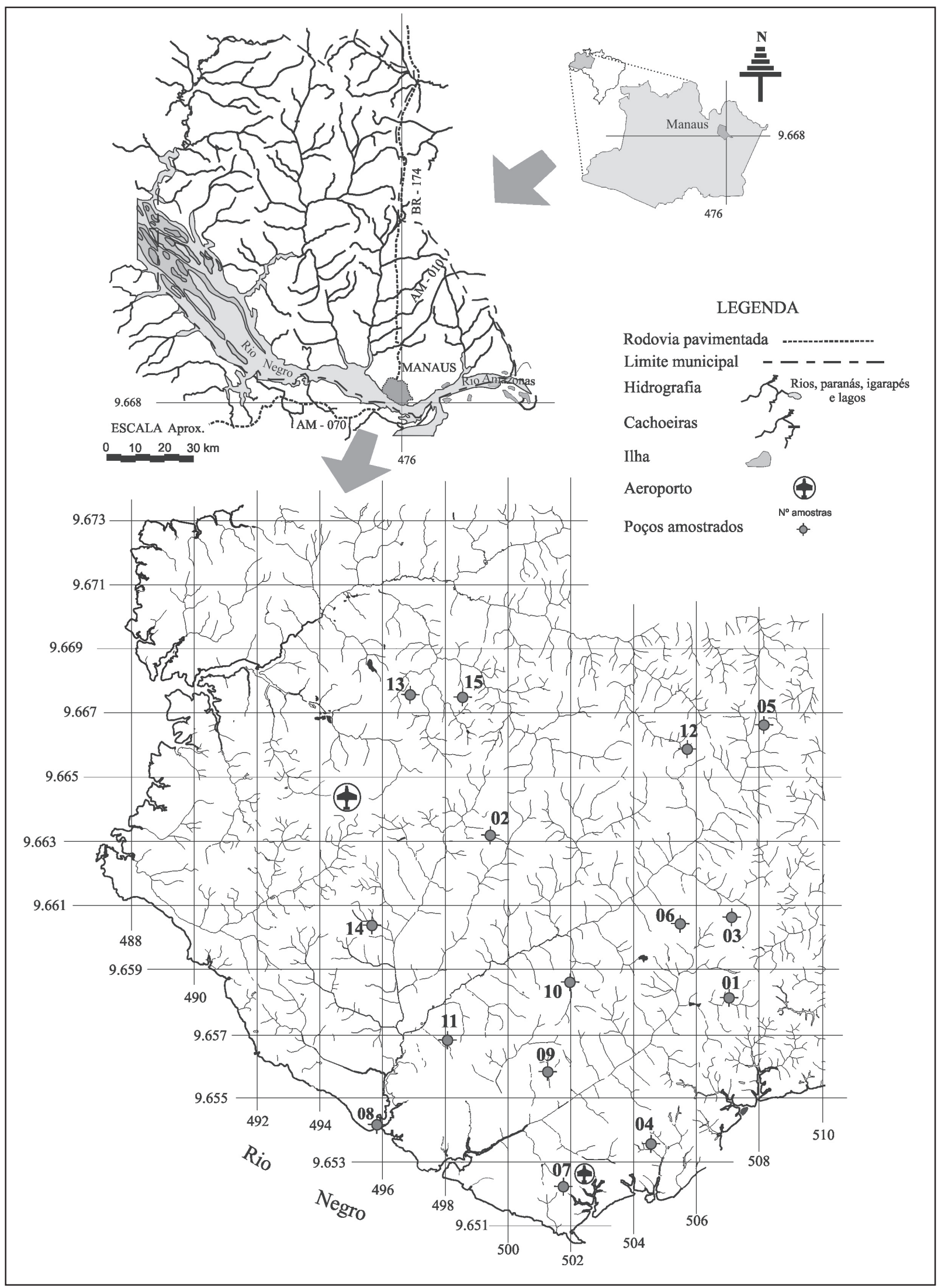

Figura 1. Mapa de localização da cidade de Manaus (AM) e dos poços amostrados. 
férrico, permanecendo a amostra em repouso por 3 dias para a floculação e posterior decantação do precipitado, no qual se encontram o urânio e outros elementos. Após a total decantação, foi retirado e desprezado, cautelosamente, por via mecânica, o máximo de sobrenadante. $\mathrm{O}$ precipitado, mais o que sobrou do sobrenadante, foi transferido para frasco de $2 \mathrm{~L}$, novo e limpo, identificado com etiqueta numerada e lacrada. A etapa seguinte consistiu em acondicionar e transferir, via aérea, as amostras para extração do urânio no LABIDRO - Laboratório de Isótopos e Hidroquímica do Departamento de Petrologia e Metalogenia do Instituto de Geociências e Ciências Exatas da UNESP - Campus de Rio Claro.

No LABIDRO, recuperou-se o precipitado acondicionado em frasco de $2 \mathrm{~L}$, centrifugando-o por 15 minutos a $2000 \mathrm{rpm}$. O precipitado foi transferido para um béquer de $80 \mathrm{~mL}$, ao qual se adicionou $\mathrm{HCl} 8 \mathrm{M}$ e 4 gotas de $\mathrm{HClO}_{4}$, conduzindo-se a uma chapa aquecedora para ser evaporado e seco. Após a secagem, o material foi redissolvido com $\mathrm{HCl} 8 \mathrm{M}$, para que ocorresse a conversão de diuranato de amônio para cloreto de uranila. Para separar o ferro do U e outros elementos, efetuou-se extração com solvente orgânico (éter di-isopropílico); a fase etérea foi descartada, estando o urânio na forma dos íons complexos $\left(\mathrm{UO}_{2} \mathrm{Cl}_{4}\right)^{2-} \mathrm{e}$ $\left(\mathrm{UO}_{2} \mathrm{Cl}_{3}\right)^{-}$e o ferro residual na forma de íons $\mathrm{FeCl}_{4}^{-}$numa solução de $\mathrm{HCl}$ 8M. Para a separação do urânio, tornou-se necessária a utilização de resina de troca iônica, tendo sido empregada a aniônica Rexyn 201 da Fisher Scientific Co., com porosidade de 50 a 100 mesh, sob a forma iônica $\mathrm{OH}^{-}$e capacidade total de troca de $1,4 \mathrm{mEq} \cdot \mathrm{mL}^{-1}$. A resina acidificada com $\mathrm{HCl} 8 \mathrm{M}$ retém o ferro e o urânio, deixando passar os alcalino-terrosos e outros elementos, e, ao se eluir a resina com $\mathrm{HNO}_{3} 7 \mathrm{M}$, consegue-se retirar o $\mathrm{Fe}^{3+}$, permanecendo adsorvido o urânio. Com a adição de $\mathrm{HCl}$ 0,1 M à coluna ocorre a eluição do urânio, pois, os íons de cloreto de uranila ( $\mathrm{UO}_{2} \mathrm{Cl}_{4}^{2-}$ ) não são estáveis nessa solução. A solução resultante é transferida para uma chapa aquecedora para evaporação até secagem, onde, ao resíduo seco, acrescenta-se $\mathrm{H}_{2} \mathrm{SO}_{4} 2 \mathrm{M}$ e o eletrólito $\left(\mathrm{NH}_{4}\right)_{2} \mathrm{SO}_{4} 2 \mathrm{M}$. A seguir, a solução foi transferida para célula de eletrodeposição (Bonotto, 1996), sendo o $\mathrm{pH}$ ajustado para 2,4 por intermédio de $\mathrm{H}_{2} \mathrm{SO}_{4}$ e $\mathrm{NH}_{4} \mathrm{OH} 2 \mathrm{M}$. Depois, submeteu-se a solução a uma corrente contínua constante de $300 \mathrm{~mA}$, por 3 horas, adicionando-se algumas gotas de $\mathrm{NH}_{4} \mathrm{OH}$ antes de se desligar o circuíto. Após a remoção do ânodo de Pt, ocorreu a deposição do urânio em cátodo consistindo de disco de aço inoxidável, o qual foi lavado com água destilada e seco em lâmpada infra-vermelha.

Todos os discos preparados foram analisados por intermédio de dois detectores semicondutores de barreira de superfície. Os resultados foram obtidos e tratados pelo programa MAESTRO II da ORTEC. Por permitir, para cada canal, um registro de um valor de energia correspondente, os dois sistemas utilizados foram calibrados por intermédio de um padrão de urânio, consistindo numa mistura de urânio natural com atividade para ${ }^{238} \mathrm{U}$ de 54,6 dpm e para ${ }^{232} \mathrm{U}^{228} \mathrm{Th}$ (traçador) de $10 \mathrm{dpm}$, conforme descrito por Bonotto (1986). A obtenção do teor de urânio dissolvido nas águas analisadas foi efetuada com base no princípio de diluição isotópica, de acordo com o descrito por Bonotto (1982), enquanto que a quantificação da razão de atividade ${ }^{234} \mathrm{U} / 238 \mathrm{U}$ foi efetuada a partir da taxa de contagem nos picos do ${ }^{238} \mathrm{U}$ e ${ }^{234} \mathrm{U}$ presentes nos espectrogramas alfa obtidos. A taxa de contagem da radiação de fundo foi monitorada periodicamente para cada sistema em uso.

\section{RESULTADOS E DISCUSSÃO}

Principais parâmetros físicos, físico-químicos e químicos De acordo com as características hidrogeológicas, todos os poços amostrados na cidade de Manaus extraem água da Formação Alter do Chão. A altitude da área de amostragem variou de 27 a 93 m, e as médias para o nível estático (N.E.) e nível dinâmico
(N.D.) foram de 45,48 m e 87,57 m, respectivamente. A vazão média foi de $89,45 \mathrm{~m}^{3} / \mathrm{h}$ (Tabela 1), apresentando correlação linear de $67 \%$ com a profundidade.

Os resultados obtidos na avaliação dos principais parâmetros físicos e físico-químicos para as águas subterrâneas estudadas estão representados na Tabela 2. Conforme se verifica, as temperaturas obtidas são relativamente homogêneas, variando de 27 a $29^{\circ} \mathrm{C}$. A temperatura média do ar corresponde a $32,5^{\circ} \mathrm{C}$, sendo que o seu valor superior em relação ao das águas subterrâneas pode ser explicado pela interpretação de Castany (1971) que considera que a água meteórica, em seu trajeto, desde a zona não saturada até a saturada, tende a entrar em equilíbrio térmico com as rochas do aqüífero. Costa et al. (2003) encontraram valor médio de $29^{\circ} \mathrm{C}$ para a temperatura da água subterrânea na área urbana de Manaus. Souza (1994) fez referência à temperatura média das águas subterrâneas em Manaus como sendo igual a $27,3^{\circ} \mathrm{C}$ e, em estudo hidrogeoquímico realizado por Tancredi et al. (1987) na ilha de Marajó - PA, a temperatura variou de 26 a $29,5^{\circ} \mathrm{C}$. Todos estes resultados são semelhantes aos encontrados neste trabalho, indicando que a temperatura atmosférica na região estudada exerce influência sobre as águas subterrâneas, pelo não confinamento dos aqüíferos, rápida infiltração das águas meteóricas ou pequena profundidade do posicionamento dos filtros dos poços amostrados.

Os valores encontrados para o $\mathrm{pH}$ variam de 4,1 a 5,4, indicando que são ácidas as águas dos poços amostrados, ou seja, elas exibem valores de $\mathrm{pH}$ inferiores ao mínimo de 6 estabelecido pela Resolução CONAMA No 20/86. Esta característica físico-química das águas estudadas possivelmente pode ser explicada em função da composição mineralógica das rochas do aqüífero, recarga rápida e processos de interação água-rocha/ solo, pois, Forti \& Moreira-Nordemann (1991) determinaram para o $\mathrm{pH}$ da água de chuva na região de floresta de terra firme valores entre 4 e 5,3 .

$\mathrm{O}$ potencial redox medido nas águas estudadas variou de +93 a +256 mV, de maneira que o seu ambiente de circulação pode ser classificado como "redutor e ácido", de acordo com o diagrama Eh-pH de Krauskopf (1972) (Figura 2). A condutividade elétrica (CE) variou de 15,1 a $82,9 \mu \mathrm{S} . \mathrm{cm}^{-1}$, valores que são baixos e indicativos de que as águas são fracamente mineralizadas. Estudos hidroquímicos realizados por Santos \& Ribeiro (1988) também evidenciaram a extrema pureza das águas naturais da região estudada, refletindo a importância do escoamento, alto índice pluviométrico e evapotranspiração. Um significante coeficiente de correlação $(r=0,62)$ foi encontrado entre a CE e a temperatura, evidenciando que a CE aumenta com a elevação da temperatura, conforme esperado (Castany, 1971). Tanto o $\mathrm{pH}$ quanto a $\mathrm{CE}$ apresentaram correlação negativa com a altitude dos poços amostrados, sugerindo um aumento nos valores relacionados com esses parâmetros, de acordo com a direção do fluxo subterrâneo na área de estudo.

Da Tabela 3 constam os resultados obtidos na análise dos principais ânions e cátions dissolvidos nas águas estudadas, onde se verifica que são baixos os valores encontrados, o maior deles correspondendo a $13,4 \mathrm{mg} . \mathrm{L}^{-1}$ para o potássio na amostra 8 . Os menores valores de bicarbonato indicam áreas de recarga coincidindo com as áreas de topografia mais elevada e crescendo de acordo com o sentido do fluxo subterrâneo. Para todas as amostras, o teor de sulfato foi inferior ao limite de detecção correspondente a $1 \mathrm{mg} . \mathrm{L}^{-1}$, verificando-se, em termos de valores médios, que o cloreto corresponde ao ânion mais abundante (média de 1 mg.L $\left.\mathrm{L}^{-1}\right)$. Porém, apesar disso, os valores obtidos para esse ânion são bem inferiores a $150 \mathrm{mg} . \mathrm{L}^{-1}$, considerado como o limite máximo para uso da água para diversas finalidades (Portaria $\mathrm{N}^{\mathrm{o}} 518$ de 25/03/04 do Ministério da Saúde). Assim, os teores de cloreto obtidos sugerem um não confinamento do aqüífero, e que as 
Tabela 1. Características principais dos poços amostrados no município de Manaus (AM).

\begin{tabular}{|c|c|c|c|c|c|c|c|c|}
\hline Amostra & $\begin{array}{c}\text { UTM } \\
\text { OESTE }\end{array}$ & $\begin{array}{c}\text { UTM } \\
\text { NORTE }\end{array}$ & $\begin{array}{l}\text { Altitude } \\
\text { (m) }\end{array}$ & $\begin{array}{l}{ }^{1} \text { Prof. } \\
\text { (m) }\end{array}$ & $\begin{array}{l}{ }^{2} \mathbf{N} . E . \\
(\mathbf{m})\end{array}$ & $\begin{array}{l}{ }^{3} \mathbf{N} . D . \\
(\mathbf{m})\end{array}$ & $\begin{array}{l}\text { Vazão } \\
\left(\mathbf{m}^{3} / \mathbf{h}\right)\end{array}$ & $\begin{array}{c}\text { Descrição litológica * } \\
\text { (m) }\end{array}$ \\
\hline 01 & 507081 & 9658088 & 79 & 153,0 & 59,60 & 77,08 & 22,53 & $\begin{array}{c}\text { 0-Ag-10,5-ArfAg-63-Ag-66-ArfAg-102- } \\
\text { Ag-104-ArM-112-ArfAg-142-Ag-143- } \\
\text { ArfAg-153 }\end{array}$ \\
\hline 02 & 503137 & 9657483 & 87 & 143,3 & 22,92 & 44,33 & 79,20 & $\begin{array}{c}\text { 0-Ag-6-Arf-21-Ag-26-Arf-50-Ag-56-Arf- } \\
\text { 71-Ag-88-Arf-102-Ag-105-Arf-118-Ag- } \\
\text { 123-Arf-143 }\end{array}$ \\
\hline 03 & 506437 & 9660228 & 55 & 202,0 & 52,37 & 114,92 & 203,80 & $\begin{array}{c}\text { 0-ArfAg-70-ArM-74-Arm-79-Ag-82-Arm- } \\
\text { 116-ArM-119-ArfAg-144-Ag-147-ArfAg- } \\
\text { 179-ArM-181-ArfAg-202 } \\
\end{array}$ \\
\hline 04 & 504255 & 9653341 & 45 & 154,0 & 48,00 & 79,07 & 29,40 & $\begin{array}{l}\text { 0-Ag-8-ArfAg-24-Arm-57-ArG-74-AgArf- } \\
\text { 83-Arf-113-Ag-126-Arf-151-Ag-154 }\end{array}$ \\
\hline 05 & 505289 & 9660237 & 60 & 228,0 & 72,30 & 114,85 & 198,00 & $\begin{array}{c}\text { 0-Ag-7-Arf-92-ArM-94-Arf-100-Ag-103- } \\
\text { Arf-139-ArM-141-Arf-175-Ag-178-Arf- } \\
\text { 215-Ag-228 } \\
\end{array}$ \\
\hline 06 & 506873 & 9663637 & 55 & 203,0 & 38,65 & 130,96 & 101,54 & $\begin{array}{l}\text { 0-Arf-38-Ag-43-Arf-101-ArM-103-Arf- } \\
\text { 130-Ag-135-Arf-162-Ag-168-Arf-203 }\end{array}$ \\
\hline 07 & 501680 & 9662182 & 83 & 152,5 & 46,80 & 100,60 & 40,04 & $\begin{array}{c}\text { 0-Ag-6-ArG-18-ArfAg-93-Ag-98-ArfAg- } \\
\text { 108-ArM-114-ArfAg-152,5 }\end{array}$ \\
\hline 08 & 495780 & 9654121 & 27 & 202,0 & 4,70 & 53,37 & 226,00 & $\begin{array}{l}\text { 0-C-8-ArG-39-ArfAg-58-ArG-63-ArfAg- } \\
\text { 82-AgArG-110-Arm-141-ArfAg-202 }\end{array}$ \\
\hline 09 & 501154 & 9655928 & 43 & 134,0 & 24,81 & 51,03 & 56,57 & 0-Arf-8-ArfAg-76-Ag-91-ArfAg-134 \\
\hline 10 & 499255 & 9663040 & 82 & 41,5 & 23,20 & 30,01 & 1,80 & $\begin{array}{c}\text { 0-Ag-10-Arf-28,5-ArfAg-30-Arf-39,5- } \\
\text { Ag-41,5 }\end{array}$ \\
\hline 11 & 498010 & 9656980 & 57 & 158,0 & 38,64 & 84,15 & 52,79 & $\begin{array}{c}\text { 0-Ag-8-Arf-36-ArM-38-ArfAg-75-Ag-78- } \\
\text { AgArf-104-Ag-110-ArfAg-158 }\end{array}$ \\
\hline 12 & 505670 & 9665899 & 55 & 223,0 & 73,10 & 115,14 & 101,53 & $\begin{array}{l}\text { 0-Ag-2-ArfAg-75,5-ArM-77-ArfAg-85- } \\
\text { Ag-99-ArM-101,5-Arf-113,5-ArM-116- } \\
\text { ArfAg-140,5-Ag-145,5-ArfAg-223 }\end{array}$ \\
\hline 13 & 496900 & 9667755 & 91 & 189,0 & 52,60 & 115,60 & 21,16 & $\begin{array}{c}\text { 0-Ag-5-Arf-60-ArM-63-Arf-113-Ag-117- } \\
\text { Arf-120-Ag-130-ArM-132-Arf-177-Ag- } \\
\text { 182-Arf-189 }\end{array}$ \\
\hline 14 & 495101 & 9660622 & 65 & 171,0 & 55,73 & 99,03 & 35,20 & $\begin{array}{c}\text { 0-Ag-7-Arf-24-Arm-29-Arf-54-Arm-57- } \\
\text { ArM-67-Arf-73-Ag-91-Arf-98-ArfAg-122- } \\
\text { Ag-141-Arf-171 }\end{array}$ \\
\hline 15 & 498687 & 9667626 & 93 & 203,0 & 68,87 & 103,46 & 172,95 & $\begin{array}{c}\text { 0-Ag-2-Arf-51-Ag-54-Arf-82-ArM-83- } \\
\text { Arf-97-Ag-102-Arf-144-Ag-146-ArfAg- } \\
\text { 163-ArM-165-ArfAg-203 }\end{array}$ \\
\hline Média & - & - & - & 170,5 & 45,48 & 87,57 & 89,45 & - \\
\hline
\end{tabular}

Tabela 2. Variáveis físicas e fisico-químicas das águas subterrâneas analisadas na cidade de Manaus (AM).

\begin{tabular}{|c|c|c|c|c|c|}
\hline Amostra & $\begin{array}{l}\text { Temperatura da água } \\
\left({ }^{\circ} \mathrm{C}\right)\end{array}$ & $\begin{array}{c}\text { Temperatura do ar } \\
\left({ }^{\circ} \mathrm{C}\right)\end{array}$ & $\begin{array}{c}\text { Condutividade elétrica } \\
\left(\mu{\left.\mathrm{s} . \mathrm{cm}^{-1}\right)}^{-1}\right.\end{array}$ & pH & $\begin{array}{c}\mathbf{E h} \\
(\mathrm{mV})\end{array}$ \\
\hline 01 & 28 & 33 & 16,3 & 5,0 & +201 \\
\hline 02 & 27 & 29 & 27,9 & 4,4 & +248 \\
\hline 03 & 28 & 33 & 26,3 & 4,8 & +207 \\
\hline 04 & 27 & 29 & 36,2 & 5,2 & +199 \\
\hline 05 & 27 & 28 & 27,0 & 4,9 & +204 \\
\hline 06 & 27 & 28 & 31,9 & 5,2 & +211 \\
\hline 07 & 27 & 34 & 18,4 & 4,1 & +256 \\
\hline 08 & 29 & 33 & 82,9 & 5,4 & +93 \\
\hline 09 & 29 & 34 & 40,2 & 5,0 & +204 \\
\hline 10 & 29 & 34 & 27,8 & 4,5 & +256 \\
\hline 11 & 28 & 34 & 15,1 & 4,5 & +97 \\
\hline 12 & 28 & 35 & 35,2 & 5,1 & +134 \\
\hline 13 & 27 & 35 & 15,7 & 4,4 & +213 \\
\hline 14 & 29 & 33 & 55,6 & 5,0 & +241 \\
\hline 15 & 27 & 35 & 29,8 & 4,9 & +205 \\
\hline Média & 27,8 & 32,5 & 32,4 & - & $+197,9$ \\
\hline
\end{tabular}




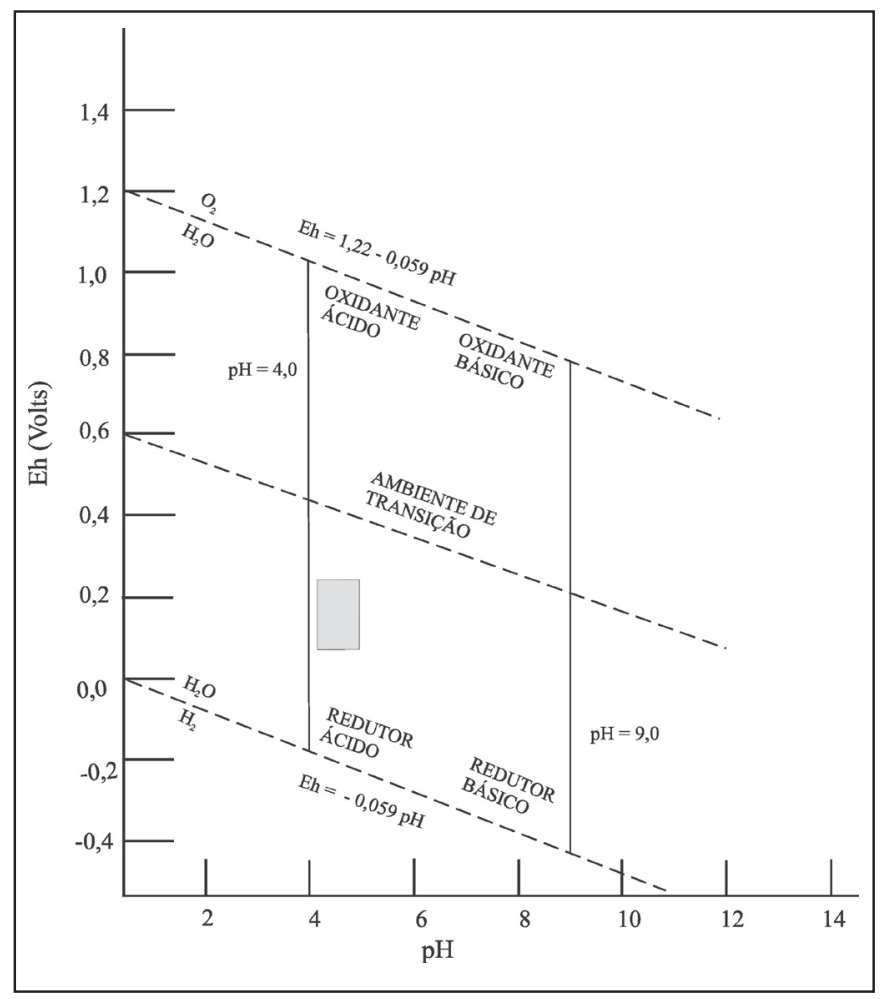

Figura 2. Diagrama Eh-pH segundo Krauskopf (1972). A área hachurada representa os valores obtidos para as amostras de águas subterrâneas de Manaus analisadas neste trabalho.

águas são recém-infiltradas, refletindo as características das águas de chuva com pouca interação com os estratos do aqüífero. Forti \& Moreira-Nordemann (1991) ao estudarem as águas de chuva da região de Manaus determinaram uma baixa concentração de cloreto, em concordância com os resultados obtidos neste trabalho. Dentre os constituintes inorgânicos que figuram nas normas de qualidade de água, o nitrato é bastante importante, devido à sua ampla distribuição, grande mobilidade em subsuperfície, estabilidade em sistemas aeróbicos de águas subterrâneas e risco à saúde humana. Santos et al. (1981) estimaram que as precipitações em área próxima de Manaus ocasionam a introdução da ordem de 3,2 kg/ha/ano de amônia e 2,5 kg/ha/ano de nitrato. Os teores de nitrato superiores a $10 \mathrm{mg} . \mathrm{L}^{-1}$ são indesejáveis na água de uso doméstico, devido a um possível efeito tóxico sobre as crianças novas, por causar cianose, porém, os valores obtidos nas amostras analisadas situaram-se entre 0,019 e $1,02 \mathrm{mg} . \mathrm{L}^{-1}$, bem abaixo do limite estabelecido pela Portaria $N^{\circ} 518$ de 25/03/04 do Ministério da Saúde.

Considerando-se os valores médios obtidos para os principais cátions, verifica-se que a sua abundância ocorre de acordo com a seqüência $\mathrm{K}^{+}>\mathrm{Na}^{+}>\mathrm{Ca}^{+2}=\mathrm{Mg}^{+2}$. Essa situação não é comum para águas subterrâneas, uma vez que o potássio ocorre em rochas numa forma não facilmente solubilizada, sendo recombinável com outros produtos de intemperismo, particularmente os minerais argilosos, conforme sugere Hem (1959) ao mostrar a tendência do potássio em estar sempre presente nos sedimentos argilosos em proporções maiores do que nas rochas ígneas. Dentre os metais alcalinos dissolvidos nas águas, o sódio costuma ser mais abundante do que o potássio, sendo os feldspatos geralmente as mais importantes fontes desse elemento, uma vez que a albita e a anortita são decompostas mais facilmente do que os feldspatos potássicos. Nas águas analisadas, os teores de sódio variaram de 0,5 a 4,5 mg. $\mathrm{L}^{-1}$, e, quando lixiviado, esse elemento tende a permanecer em solução, pela grande solubilidade de seus compostos. De acordo com Garrels (1960), altas concentrações de potássio só ocorrem em regiões onde não há suficientes silicatos de alumínio capazes de sua fixação. Santos \& Ribeiro (1988) consideram que a alta concentração de potássio, sódio e magnésio nos rios de água preta da Amazônia está relacionada com o intemperismo de feldspatos, lavagem das folhas, caules, troncos e decomposição orgânica.

Os teores de cálcio variaram de 0,001 a 5,45 mg.L ${ }^{-1}$ e, apesar de ser baixa a presença de bicarbonato nas águas estudadas, verifica-se que esse ânion favorece a solubilização de cálcio, pois, obteve-se uma correlação de $80 \%$ entre esses parâmetros. Análises de águas dos troncos e de subsuperfície conduzidas por Santos et al. (1981) em ecossistemas florestais perto de Manaus sugeriram que o cálcio circula num sistema fechado, onde se torna imobilizado, principalmente, nas folhas mais velhas das plantas (freqüentemente na forma de oxalato de cálcio, fosfato

Tabela 3. Teores dos principais ânions e cátions (em mg. $L^{-1}$ ) dissolvidos nas águas subterrâneas da cidade de Manaus analisadas neste trabalho.

\begin{tabular}{|c|c|c|c|c|c|c|c|c|c|c|c|c|}
\hline Amostra & $\begin{array}{c}\mathrm{Cl}_{(\mathrm{mg}} \\
\underset{\left.\mathrm{L}^{-1}\right)}{ }\end{array}$ & $\begin{array}{l}\mathrm{NO}_{3}^{-} \\
\left(\mathrm{mg}^{-1}\right. \\
\left.\mathrm{L}^{-1}\right)\end{array}$ & $\begin{array}{l}\mathrm{SO}_{4}^{2-} \\
\left(\mathrm{mg}^{2-}\right. \\
\left.\mathrm{L}^{-1}\right)\end{array}$ & $\begin{array}{c}\text { Alcal. } \\
\left(\mathrm{mgHCO}_{3} \cdot \mathrm{L}^{-1}\right)\end{array}$ & $\underset{\left(\mathbf{m g} . \mathrm{L}^{-1}\right)}{\mathbf{N H}^{+}}$ & $\left(\mathrm{mg}^{\mathrm{ma}^{2+}} \mathrm{L}^{-1}\right)$ & $\underset{\left(\mathbf{m g} \cdot \mathrm{L}^{-1}\right)}{\mathbf{M g}^{2+}}$ & $\underset{\left(\mathbf{m g} \cdot \mathrm{L}^{-1}\right)}{\mathrm{K}^{+}}$ & $\underset{\left(\mathbf{m g} \cdot \mathrm{L}^{-1}\right)}{\mathrm{Na}^{+}}$ & $\underset{\left(\mathbf{m g} \cdot \mathrm{L}^{-1}\right)}{\mathrm{Fe}^{3+}}$ & $\begin{array}{l}\text { Fe total } \\
\left(\mathrm{mg} \cdot \mathrm{L}^{-1}\right)\end{array}$ & $\begin{array}{l}\text { Dureza } \\
\left(\mathrm{mg} . \mathrm{L}^{-1}\right)\end{array}$ \\
\hline 01 & 0,92 & 0,12 & $<1,0$ & 0,61 & 0,03 & 0,19 & 0,39 & 5,9 & 0,7 & 0,001 & 0,001 & 2,35 \\
\hline 02 & 1,27 & 0,22 & $<1,0$ & $<0,10$ & 0,02 & 0,00 & 0,13 & 0,1 & 1,7 & 0,001 & 0,001 & 0,62 \\
\hline 03 & 0,71 & 0,01 & $<1,0$ & 0,61 & 0,01 & 0,72 & 0,48 & 5,8 & 0,6 & 0,001 & 0,001 & 4,22 \\
\hline 04 & 0,71 & 0,03 & $<1,0$ & 1,22 & 0,02 & 1,04 & 0,42 & 8,3 & 0,7 & 0,001 & 0,001 & 4,85 \\
\hline 05 & 0,71 & 0,03 & $<1,0$ & 1,22 & 0,02 & 0,38 & 0,52 & 6,0 & 0,6 & 0,001 & 0,191 & 3,47 \\
\hline 06 & 0,78 & 0,05 & $<1,0$ & 1,22 & 0,03 & 0,38 & 0,76 & 8,8 & 0,8 & 0,001 & 0,001 & 4,58 \\
\hline 07 & 0,71 & 0,08 & $<1,0$ & $<0,10$ & 0,03 & 0,08 & 0,02 & 0,4 & 0,8 & 0,001 & 0,001 & 0,35 \\
\hline 08 & 0,71 & 0,02 & $<1,0$ & 3,05 & 0,01 & 5,45 & 2,82 & 13,4 & 1,3 & 0,001 & 0,001 & 28,03 \\
\hline 09 & 0,78 & 0,26 & $<1,0$ & 0,16 & 0,01 & 0,54 & 0,60 & 7,5 & 1,7 & 0,001 & 0,001 & 4,27 \\
\hline 10 & 0,99 & 0,45 & $<1,0$ & $<0,10$ & 0,02 & 0,00 & 0,21 & 0,1 & 2,9 & 0,001 & 0,001 & 0,97 \\
\hline 11 & 0,85 & 0,04 & $<1,0$ & $<0,10$ & 0,05 & 0,28 & 0,13 & 7,2 & 0,5 & 0,001 & 0,001 & 1,42 \\
\hline 12 & 0,71 & 0,01 & $<1,0$ & 1,83 & 0,05 & 0,88 & 0,54 & 8,5 & 0,6 & 0,001 & 0,001 & 4,93 \\
\hline 13 & 1,27 & 0,06 & $<1,0$ & $<0,10$ & 0,10 & 0,40 & 0,01 & 0,5 & 0,8 & 0,001 & 0,001 & 1,20 \\
\hline 14 & 3,05 & 1,02 & $<1,0$ & 1,83 & 0,03 & 1,28 & 0,40 & 2,7 & 4,5 & 0,001 & 0,001 & 5,42 \\
\hline 15 & 0,85 & 0,03 & $<1,0$ & 1,22 & 0,06 & 0,65 & 0,28 & 7,8 & 0,5 & 0,001 & 0,001 & 3,11 \\
\hline Média & 1,00 & 0,16 & $<1,0$ & 0,86 & 0,04 & 0,82 & 0,52 & 5,5 & 1,2 & 0,001 & 0,014 & 4,66 \\
\hline
\end{tabular}


de cálcio e sais orgânicos). O magnésio é um elemento de importância nas rochas ferromagnesianas e ultrabásicas, tendo sido o maior valor determinado para a amostra 8 , assim como verificado para o potássio e cálcio. $\mathrm{O}$ argilo mineral dominante nos solos da região é a caolinita (Damião et al., 1972). O coeficiente de correlação entre o cálcio e magnésio é 0,95 , indicando, assim, similar atuação dos processos intempéricos para a lixiviação desses elementos. A dureza é um parâmetro que leva em conta a presença de cálcio e magnésio, principalmente sob a forma de bicarbonatos, tendo sido encontrados valores entre 0,36 e 28,03 mg.L. $\mathrm{L}^{-1}$, o maior deles para a amostra 8 , conforme também verificado para o cálcio, magnésio e bicarbonato. De acordo com a classificação de Sawyer \& McCarty (1967), as águas subterrâneas estudadas são do tipo "moles". Quanto ao ferro dissolvido nas águas, duas espécies ocorrem comumente, isto é, o íon ferroso e o férrico, tendo sido encontrado um valor de $0,001 \mathrm{mg} . \mathrm{L}^{-1}$ para o ferro férrico em todas as amostras analisadas. Apenas o Fe total na amostra $5\left(0,19 \mathrm{mg} . \mathrm{L}^{-1}\right)$ se diferenciou em relação ao obtido para as demais amostras $\left(0,001 \mathrm{mg} . \mathrm{L}^{-1}\right)$, tendo sido possivelmente originado por alguma contaminação da tubulação do poço. Souza (1994) também verificou a ausência de ferro nas águas subterrâneas em Manaus, tendo Tancredi (1996) sugerido que o teor de ferro relativamente baixo reflete a elevada taxa de circulação (renovação) da água subterrânea no sistema hidrológico da Formação Alter do Chão. Mapas de isovalores de cálcio, magnésio, potássio, dureza e bicarbonato foram construídos a partir dos resultados obtidos neste trabalho, conforme ilustra a Figura 3. Se informações hidrogeológicas e topográficas fossem adicionadas a estes mapas, então, seria possível verificar que os valores relacionados a estes parâmetros aumentam de acordo com a direção do fluxo subterrâneo (decréscimo da altitude).

Para o agrupamento das águas com características similares, utilizou-se o diagrama semi-logarítmico de Schoeller (1962), o qual permitiu estabelecer um grupo de amostras com $\mathrm{Na}^{+}+\mathrm{K}^{+}>\mathrm{Ca}^{+2}>\mathrm{Mg}^{+2}$ e outro com $\mathrm{Na}^{+}+\mathrm{K}^{+}>\mathrm{Mg}^{+2}>\mathrm{Ca}^{+2}$, o que evidenciou a predominância de $\mathrm{Na}^{+}+\mathrm{K}^{+}$nas águas, que diferem nas proporções relativas de $\mathrm{Ca}^{+2} \mathrm{e} \mathrm{Mg}^{+2}$ (Figura 4). As mesmas tendências para a maioria dos íons foram também verificadas por Santos \& Ribeiro (1988) para as águas do rio Negro e por Tancredi (1996) para as águas subterrâneas de Santarém. O emprego de diagrama parcial de Piper (1944) possibilitou efetuar a classificação química das águas, verificando-se que, do ponto de vista dos cátions dissolvidos, a grande maioria é potássica ou sódica, ocorrendo duas delas com caráter misto (cálcio-potássica). Quanto aos ânions dissolvidos, nota-se que o cloreto é predominante, refletindo também sua importância naquelas amostras com caráter misto, pois, somente uma não segue esse padrão, sendo classificada como bicarbonatada (Figura 5).

Assim, quanto à hidroquímica elementar, os valores obtidos foram sempre inferiores aos limites estabelecidos pelos padrões de potabilidade recomendados pela Portaria $\mathrm{N}^{\circ} 518$ de 25/03/04 do Ministério da Saúde, inserindo-se no contexto de que a maior parte das águas subterrâneas, quando suficientemente pobres em sais minerais, são potáveis e recomendáveis para o uso, a menos que se encontrem contaminadas. Convém apenas ressaltar que a amostra 8 apresenta os maiores valores de $\mathrm{pH}, \mathrm{CE}$, dureza, magnésio, potássio, bicarbonato e cálcio, os quais podem estar relacionados com a proximidade do nível estático (NE) à superfície do terreno, poluição, pequena área de recarga, ou, simplesmente, processos de interação água/rocha-solo. É nesse contexto que também podem ser considerados os valores mais elevados de cloreto, sódio e nitrato determinados para a amostra 14 e do íon amônio para a amostra 13, pois, nesses locais, há ocorrência de um grande lixão (amostra 13) e de acentuada concentração populacional sem apropriadas condições de saneamento (amostra 14).
Urânio dissolvido e razão de atividade ${ }^{234} U{ }^{238} \mathbf{U}$ A concentração de urânio dissolvido nas amostras analisadas variou de 0,003 a $1,1 \mu \mathrm{g} . \mathrm{L}^{-1}$ (ppb) e a razão de atividade ${ }^{234} \mathrm{U} /{ }^{238} \mathrm{U}(\mathrm{RA}) \mathrm{de}$ 1,2 a 4,4 (Tabela 4). Durante a infiltração das águas meteóricas, ocorrem interações água/rocha-solo, as quais, frequentemente, resultam em razões de atividade ${ }^{234} U /{ }^{238} U$ para o urânio dissolvido maiores que a unidade, em virtude da lixiviação preferencial de ${ }^{234} \mathrm{U}$ em relação ${ }^{238} \mathrm{U}$, mecanismo que pode explicar os valores encontrados para as amostras analisadas.

Cowart \& Osmond (1980) classificaram bidimensionalmente os sistemas de águas subterrâneas para a caracterização de zonas de acumulação de urânio, de acordo com a concentração de urânio dissolvido e RA. Segundo a classificação proposta, as águas subterrâneas na Formação Alter do Chão pertencem a um sistema "normal redutor" (Figura 6). Isto significa que características redutoras predominam no ambiente de circulação daquelas águas, ocorrendo lixiviação de litologias exibindo baixa concentração de urânio, pois, em nenhum caso, obteve-se teor de urânio dissolvido superior a 1,1 $\mu \mathrm{g} . \mathrm{L}^{-1}$ (ppb). A mesma classificação "redutora" foi obtida a partir da inserção dos dados obtidos no diagrama Eh-pH (Krauskopf, 1972) (Figura 2).

De acordo com Bowie \& Plant (1983), o urânio lixiviado das rochas sob condições oxidantes pode sofrer precipitação num ambiente redutor, durante modificações nas condições de óxi-redução. Esse comportamento geoquímico também afeta a razão de atividade ${ }^{234} \mathrm{U} /{ }^{238} \mathrm{U}$, tendo sido sugerido por Andrews \& Kay (1983) e Ivanovich et al. (1991), dentre outros, modelos visando a estimativa do tempo de residência das águas subterrâneas com base nas modificações da razão de atividade ${ }^{234} \mathrm{U} /{ }^{238} \mathrm{U}$ com o tempo para o urânio dissolvido, na medida em que ocorre sua migração para zonas redutoras caracterizadas por pouca modificação no teor de urânio dissolvido. Ivanovich et al. (1991) aplicaram com sucesso o modelo isotópico de urânio na datação de águas subterrâneas de aqüífero situado na Bacia do Rio Milk, Alberta, Canadá, encontrando um longo tempo de residência correspondente a 460.000 anos. Uma das premissas utilizadas por Ivanovich et al. (1991) baseou-se na constatação de que não ocorria dissolução de ${ }^{238} \mathrm{U}$ em zonas redutoras do aqüífero estudado, situadas após barreiras de óxi-redução, e que a razão de atividade ${ }^{234} \mathrm{U} /{ }^{238} \mathrm{U}$ naquelas zonas mantinha condições de estado estacionário, de acordo com as quais ocorria diminuição do excesso de ${ }^{234} \mathrm{U}$ em solução condizente com a lei exponencial do decaimento radioativo. Estes processos estariam ocorrendo num segmento de aproximadamente $60 \mathrm{~km}$ do aqüífero situado na Bacia do Rio Milk, sendo que a diminuição do excesso de ${ }^{234} \mathrm{U}$ em solução seguia a direção do fluxo das águas subterrâneas.

Dentre outras abordagens cronológicas propostas em literatura para a determinação da idade das águas subterrâneas a partir dos isótopos de urânio ${ }^{234} \mathrm{U}$ e ${ }^{238} \mathrm{U}$ pode ser citada aquela empregada por Gomes (1978) no estudo hidroquímico realizado nas águas subterrâneas do Bambuí (Bahia). O autor utilizou modelo no qual à medida que aumenta a RA, verifica-se acréscimo no tempo de residência das águas subterrâneas. Os dados relativos aos isótopos de urânio dissolvidos nas águas foram também usados na avaliação de áreas de recarga dos aqüíferos estudados.

A superfície topográfica, direção do fluxo subterrâneo e a distribuição da razão de atividade ${ }^{234} U{ }^{238} U$ para as águas subterrâneas da cidade de Manaus estão representadas na Figura 7. A direção do fluxo da água subterrânea diverge dos poços com nível hidrostático mais elevado em relação à topografia da área de estudo. O sentido do fluxo subterrâneo diverge, preferencialmente, na porção centro-noroeste (Figura 7). Os maiores valores da razão de atividade ${ }^{234} \mathrm{U} /{ }^{238} \mathrm{U}$ ocorrem nas áreas de maior altitude, verificando-se, no geral, o seu decréscimo de acordo com o sentido do fluxo subterrâneo. A RA tende a diminuir ao lon- 


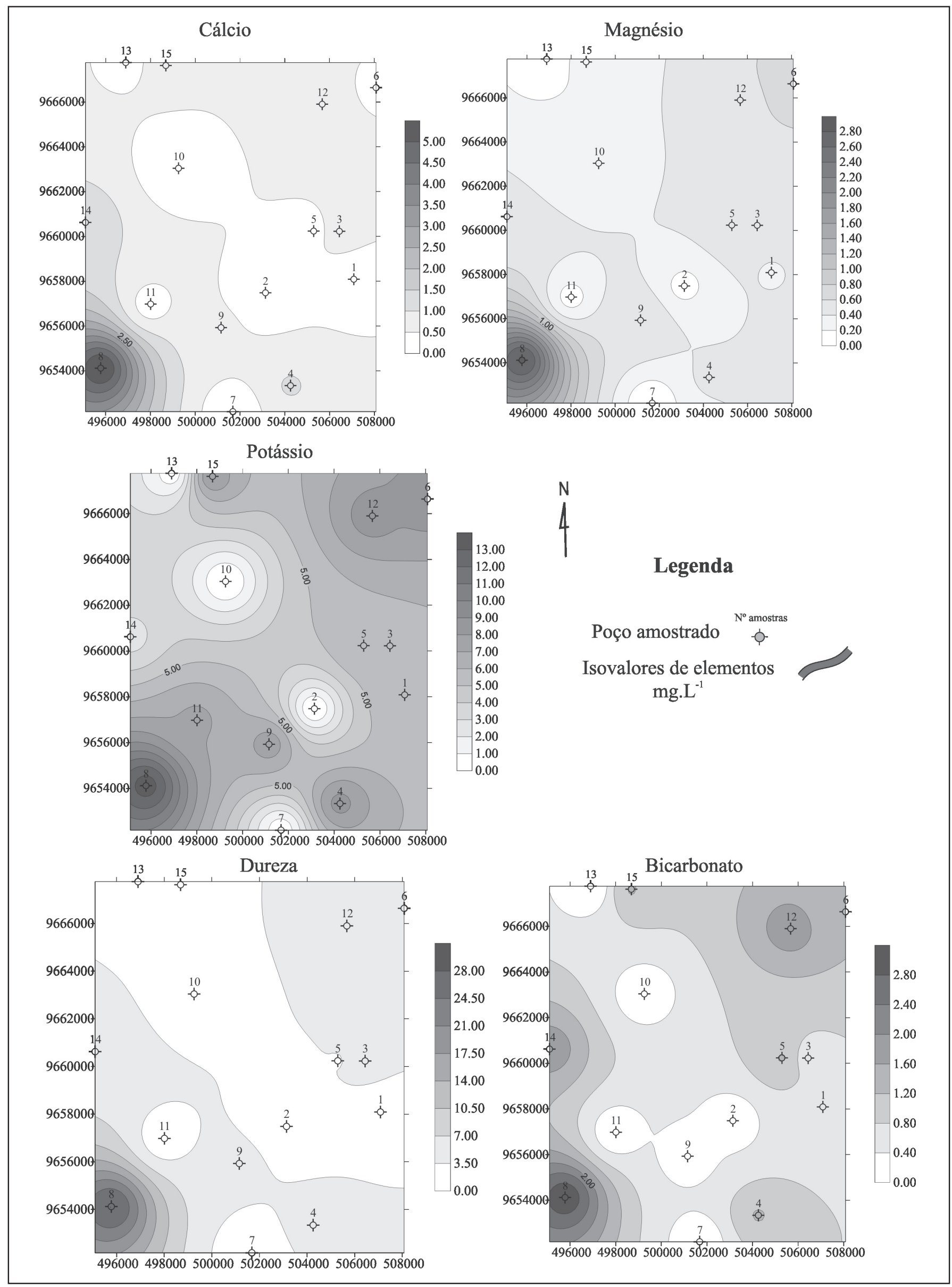

Figura 3. Mapas de isovalores de cálcio, magnésio, potássio, dureza e bicarbonato das águas subterrâneas da cidade de Manaus analisadas neste trabalho. 
(A)

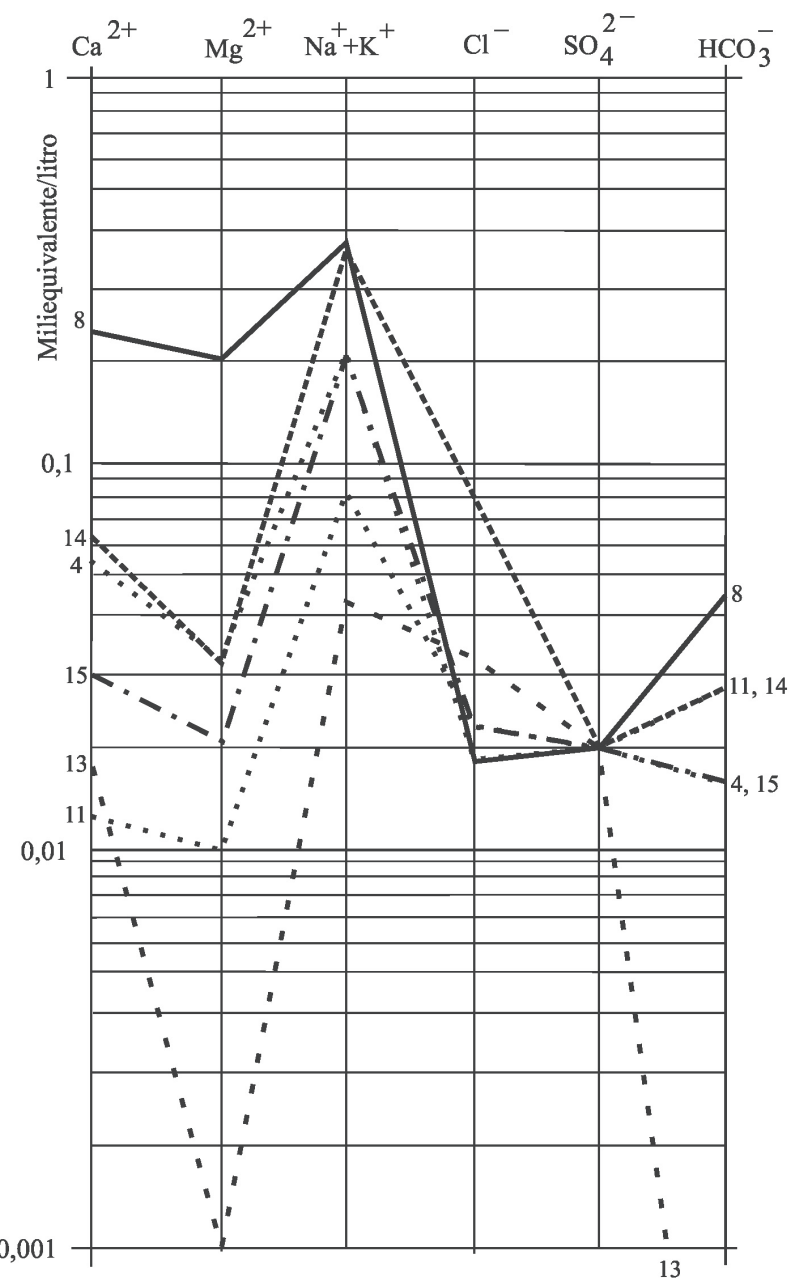

(B)

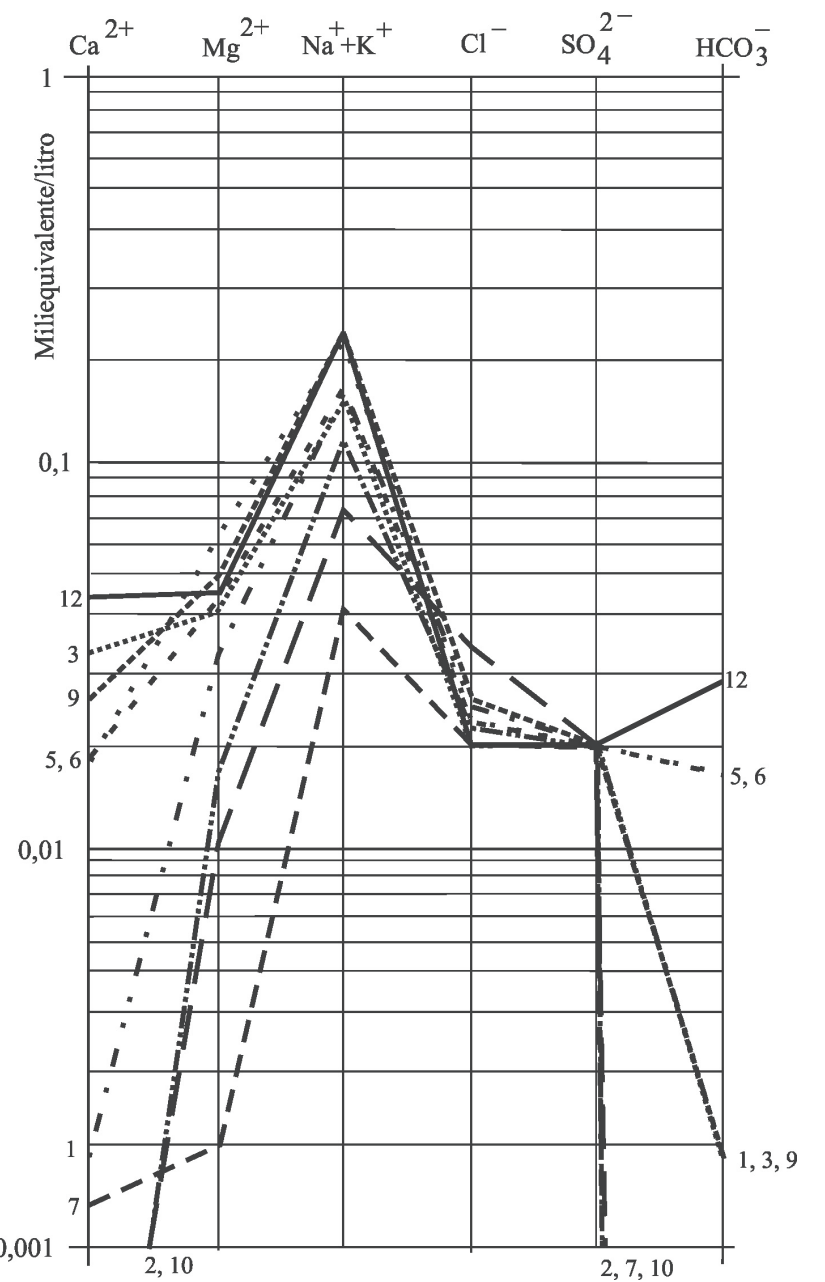

Figura 4. Diagrama de Schoeller (1962) para as amostras de águas subterrâneas de Manaus analisadas neste trabalho com concentrações de (A) $\mathrm{Na}^{+}+\mathrm{K}^{+}>\mathrm{Ca}^{+2}>\mathrm{Mg}^{+2}$ e (B) $\mathrm{Na}^{+}+\mathrm{K}^{+}>\mathrm{Mg}^{+2}>\mathrm{Ca}^{+2}$.

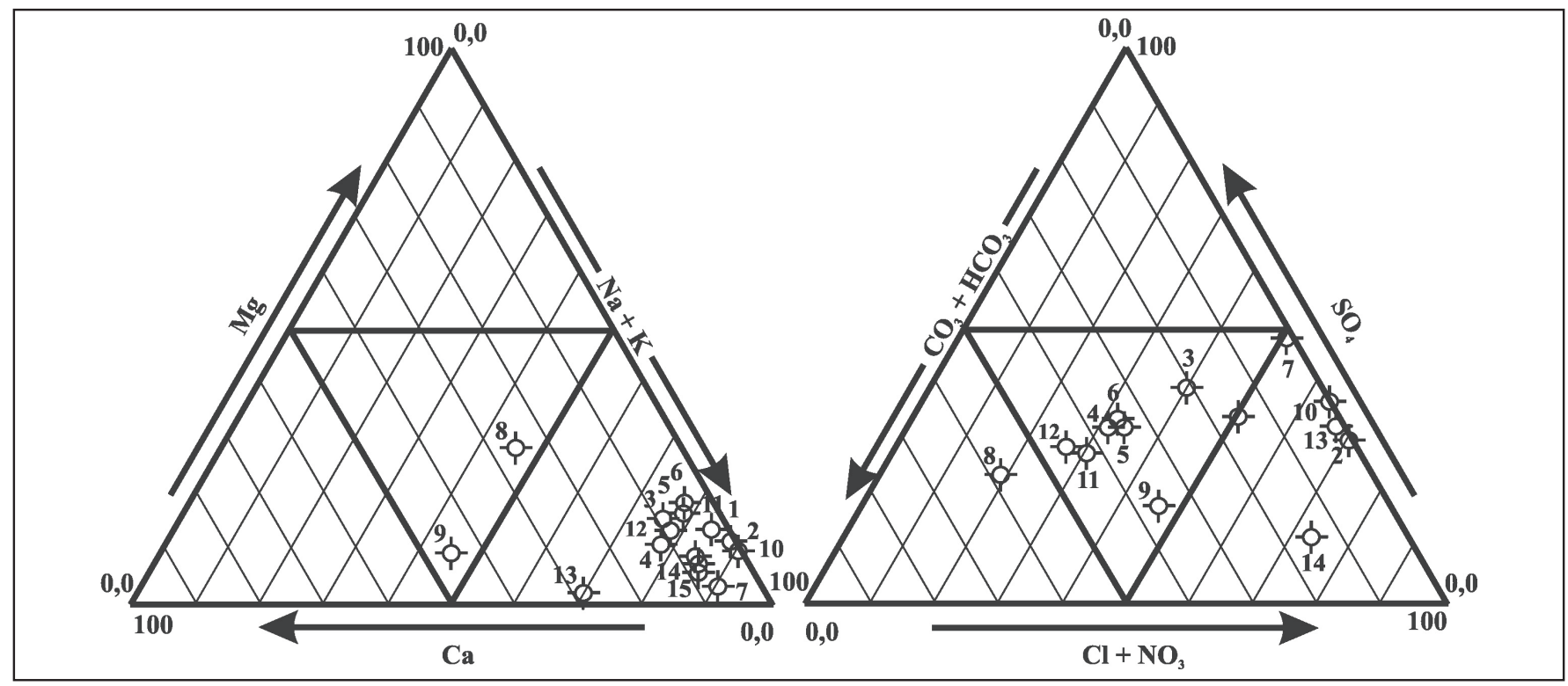

Figura 5. Representação dos dados obtidos para as amostras de águas subterrâneas de Manaus analisadas neste trabalho em diagrama parcial de Piper (1944). 
Tabela 4. Teor de urânio dissolvido e razão de atividade ${ }^{234} U{ }^{238} U$ para as amostras de águas subterrâneas de Manaus analisadas neste trabalho.

\begin{tabular}{|c|c|c|c|c|}
\hline Amostra & $\begin{array}{l}\text { Volume } \\
\text { (L) }\end{array}$ & $\begin{array}{c}\text { Tempo de Contagem } \\
\text { (segundos) }\end{array}$ & $\begin{array}{c}\text { R.A. } \\
{ }^{234} \mathbf{U}^{/ 238} \mathbf{U}^{*}\end{array}$ & $\begin{array}{c}\text { Urânio Dissolvido } \\
\left(\mu \mathrm{g} . \mathrm{L}^{-1} \mathrm{ou} \text { ppb }\right)^{*}\end{array}$ \\
\hline 01 & 20 & 338186,34 & 1,30 & 0,049 \\
\hline 02 & 20 & 326105,54 & 3,97 & 0,003 \\
\hline 03 & 20 & 260031,42 & 3,26 & 0,020 \\
\hline 04 & 20 & 178139,64 & 1,65 & 0,205 \\
\hline 05 & 20 & 266616,08 & 3,22 & 0,023 \\
\hline 06 & 20 & 172604,10 & 1,20 & 1,100 \\
\hline 07 & 20 & 260079,16 & 2,35 & 0,083 \\
\hline 08 & 20 & 359469,96 & 2,52 & 0,025 \\
\hline 09 & 20 & 324634,88 & 2,47 & 0,004 \\
\hline 10 & 20 & 338217,68 & 4,41 & 0,034 \\
\hline 11 & 20 & 266649,70 & 3,25 & 0,005 \\
\hline 12 & 20 & 169686,24 & 1,58 & 0,094 \\
\hline 13 & 20 & 304838,46 & 3,88 & 0,005 \\
\hline 14 & 20 & 359388,90 & 2,42 & 0,013 \\
\hline 15 & 20 & 324673,60 & 1,25 & 0,717 \\
\hline Média & 20 & - & 2,55 & 0,158 \\
\hline
\end{tabular}

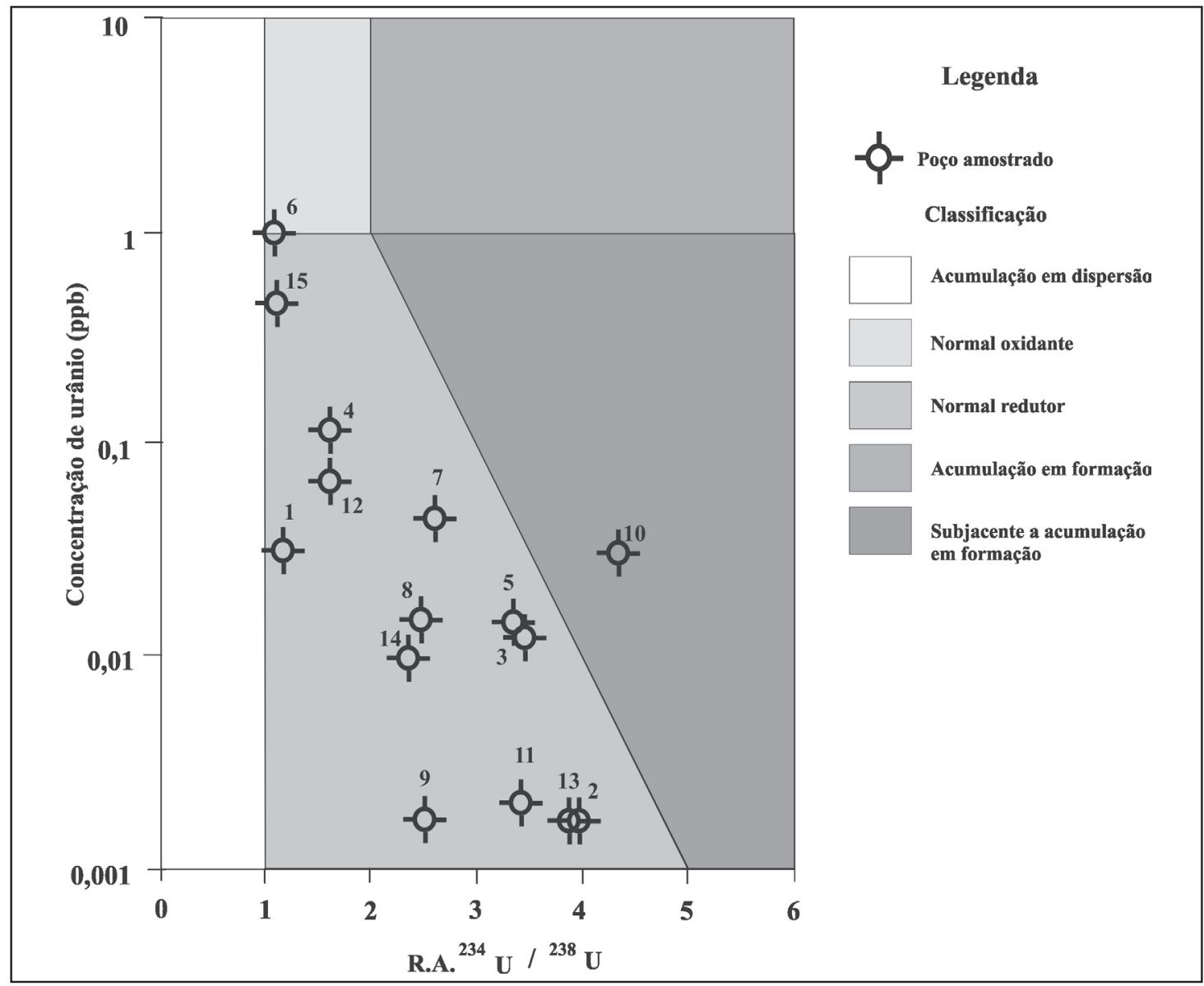

Figura 6. Classificação das amostras de águas subterrâneas de Manaus analisadas neste trabalho, baseada na concentração de urânio dissolvido e razão de atividade ${ }^{234} U^{238} U$, de acordo com o diagrama de Cowart \& Osmond (1980). 


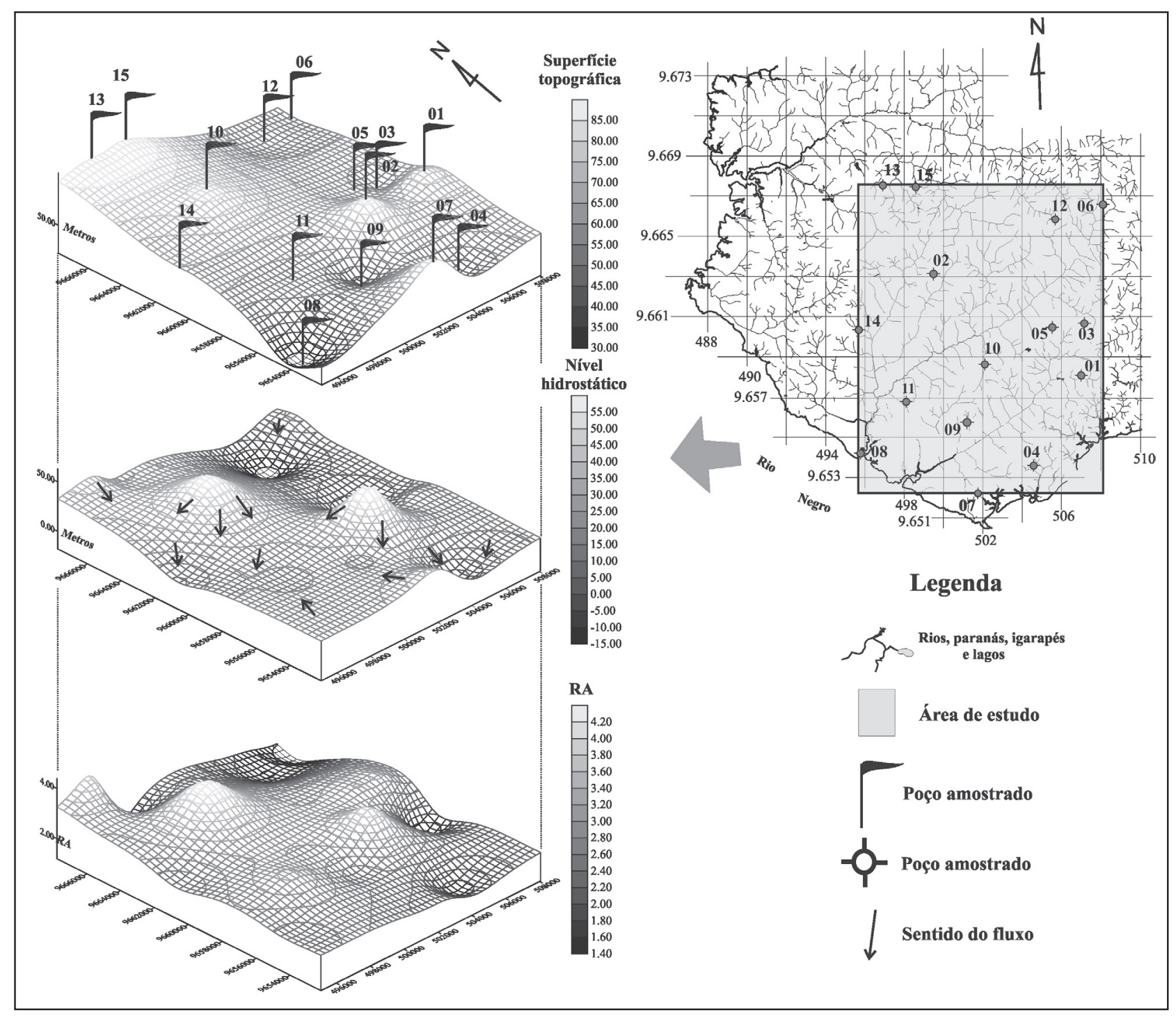

Figura 7. Blocos diagramas da superficie topográfica (em metros), contendo a localização dos poços amostrados, a posição do nível hidrostático (em metros), a direção do fluxo subterrâneo, e a distribuição da razão de atividade ${ }^{234} U^{238} U$ nas águas subterrâneas da cidade de Manaus analisadas neste trabalho.

go das direções de fluxo relacionadas com as amostras de água subterrânea dos poços 10 e 14 e poços 11 e 8 . Em princípio, essas tendências favoreceriam a aplicação do modelo isotópico de urânio descrito por Ivanovich et al. (1991), o qual permitiria estimar tempos de residência correspondentes a 317.000 e 137.000 anos, respectivamente. Contudo, esses valores são incompatíveis com as informações hidrogeológicas disponíveis para a área de estudo, sugerindo que as condições geoquímicas ocorrendo no município de Manaus diferem daquelas da Bacia do Rio Milk, sendo, porisso, inviável a aplicação do modelo cronológico baseado no urânio dissolvido.

$\mathrm{O}$ teor de urânio dissolvido e a razão de atividade ${ }^{234} \mathrm{U} /{ }^{238} \mathrm{U}$ nas águas subterrâneas do município de Manaus estão inversamente relacionados, conforme indica o coeficiente de correlação entre esses parâmetros, correspondente a $-0,60$ (Tabela 4). Por outro lado, foi constatada uma tendência de enriquecimento de ${ }^{234} U$ nas águas na medida em que aumenta a espessura da zona vadosa $(r=0,54)$, pois, isto favorece a lixiviação preferencial do ${ }^{234} \mathrm{U}$ relativamente à do ${ }^{238} \mathrm{U}$, uma vez que a área superficial aumenta, e, conseqüentemente, os efeitos das interações água/ rocha-solo. Além disso, a lixiviação de ${ }^{234} \mathrm{Th}$, descendente do ${ }^{238} \mathrm{U}$, tende a ser mais acentuada na medida em que a acidez aumenta. Este nuclídeo, por sua vez, apresenta uma meia-vida curta (24 dias), decaindo para ${ }^{234} \mathrm{~Pa}$ (meia-vida $=6,7$ horas) $\mathrm{e}$ este para ${ }^{234} \mathrm{U}$. Assim, a lixiviação preferencial de ${ }^{234} \mathrm{U}$ em relação à de ${ }^{238} \mathrm{U}$ e a contribuição crescente do ${ }^{234} \mathrm{Th}$ na produção de ${ }^{234} \mathrm{U}$ na medida em que a acidez aumenta justificam a tendência de enriquecimento de ${ }^{234} \mathrm{U}$ nas águas, de acordo com a diminuição do $\mathrm{pH}(\mathrm{r}=-0,61)$. Portanto, a relação inversa entre o teor de urânio dissolvido e a RA pode ser explicada pelo fato de que, na área investigada, com a redução do $\mathrm{pH}$, ocorre um aumento na razão de atividade ${ }^{234} \mathrm{U} /{ }^{238} \mathrm{U}$ decorrente da produção de ${ }^{234} \mathrm{U}$ por ${ }^{234} \mathrm{Th}$. Este efeito não é notado para o ${ }^{238} \mathrm{U}$, que é o progenitor da série de decaimento $(4 n+2)$, porém, torna-se evidente para os dados de RA, que estão diretamente relacionados com a seguinte sucessão de desintegrações alfa e beta: ${ }^{238} \mathrm{U}(\alpha) \rightarrow{ }^{234} \mathrm{Th}\left(\beta^{-}\right) \rightarrow$ ${ }^{234} \mathrm{~Pa}\left(\beta^{-}\right) \rightarrow{ }^{234} \mathrm{U}(\alpha)$. Estes fatores geoquímicos atuantes na área investigada limitam a aplicação do modelo isotópico de urânio descrito por Ivanovich et al. (1991) para a datação de águas subterrâneas, o qual, portanto, não pode ser utilizado no município de Manaus com este propósito. Porém, os dados isotópicos de urânio dissolvido são considerados apropriados como ferramenta para a prospecção hidrogeoquímica de jazidas de urânio, uma vez que o diagrama ilustrado na Figura 6 é plausível para expli- 
car a baixa concentração de urânio dissolvido encontrada nas águas estudadas.

Para a população em geral, a ingestão diária do composto solúvel e insolúvel de urânio não pode ultrapassar $0,5 \mu \mathrm{g} \cdot \mathrm{kg}^{-1} \mathrm{e}$ $5,0 \mu \mathrm{g} . \mathrm{kg}^{-1}$ do peso corporal, respectivamente. Do ponto de vista da potabilidade das águas, o valor limite para a ingestão de urânio dissolvido corresponde a $2 \mu \mathrm{g} . \mathrm{L}^{-1}$ (WHO, 2005). O critério empregado no Brasil é baseado na Portaria No 36 de 19/01/90 do Ministério da Saúde, a qual estabelece o valor de referência de $0,1 \mathrm{~Bq} \cdot \mathrm{L}^{-1}$ e $1 \mathrm{~Bq} \cdot \mathrm{L}^{-1}$ para a radioatividade alfa e beta total, respectivamente. Para se concluir sobre a potabilidade da água, devem ser aplicados os critérios da CNEN (1988) que estabelecem os limites de ingestão anual para inúmeros radionuclídeos, inclusive ${ }^{238} \mathrm{U}$ e ${ }^{234} \mathrm{U}$. Todas as águas analisadas neste trabalho são utilizadas para fins de consumo humano, de maneira que os padrões de qualidade relativos ao urânio podem ser empregados para avaliar sua potabilidade. O maior teor de urânio dissolvido dentre todas as amostras analisadas correspondeu a $1,1 \mu \mathrm{g} . \mathrm{L}^{-1}$ (Tabela 4), que é um valor inferior ao máximo correspondente a $2 \mu \mathrm{g} . \mathrm{L}^{-1}$, conforme estabelecido pela Organização Mundial de Saúde (WHO, 2005).

Agradecimentos Os autores agradecem ao Instituto Nacional de Pesquisas da Amazônia e ao Departamento de Petrologia e Metalogenia da Universidade Estadual Paulista pelo auxílio no desenvolvimento deste trabalho e, sobretudo, à FAPESP pelo apoio financeiro disponibilizado. Um revisor anônimo também é agradecido pelas oportunas sugestões apresentadas.

\section{Referências}

Andrews J.N. \& Kay R.L.F. 1983. The U contents and 234U/238U activity ratios of dissolved uranium in groundwater from some Triassic sandstones in England. Isotope Geoscience, 1:101-117.

APHA (American Public Health Association) (Ed.) 1985. Standard methods for the examination of water and wastewater. 16 ed., APHA, Washington.

Barbosa G.V., Costa R.C.V., Natali Filho T., Oliveira A.A.B., Garcia M.G.L. 1978. Geomorfologia. Brasília, DNPM, 18, p. 167-244.

Bonotto D.M. 1982. Aplicação dos dados do fracionamento isotópico 234U/238U nos problemas geoquímicos dos aqüiferos de Águas da Prata (SP). Dissertação de Mestrado, Instituto Astronômico e Geofísico, Universidade de São Paulo, 161 p.

Bonotto D.M. 1986. Aplicações hidrogeoquímicas dos isótopos naturais das séries do U (4n+2) e Th (4n) no Morro do Ferro, Poços de Caldas $(M G)$. Tese de Doutorado, Instituto Astronômico e Geofísico, Universidade de São Paulo, 377 p.

Bonotto D.M. 1996. Comportamento hidrogeoquímico do 222Rn e isótopos de urânio $238 U$ e $234 U$ sob condições controladas de laboratório e em sistemas naturais. Tese de Livre Docência, Instituto de Geociências e Ciências Exatas, Universidade Estadual Paulista, $223 \mathrm{p}$.

Bowie S.H.U. \& Plant J.A. 1983. Natural radioactivity in the environment. In: I. Thornton (ed.) Applied environmental geochemistry. Academic Press, London, $501 \mathrm{p}$.

Caputo M.V., Rodriguez R., Vasconcelos D.N.N. 1972. Nomenclatura estratigráfica da bacia do Amazonas; histórico e atualização. In: SBG, Congr. Bras.Geol., 26, Anais, v. 3, p. 35-46.

Castany G. (Ed.) 1971. Tratado prático de las águas subterráneas. Omega, Barcelona, $672 \mathrm{pp}$.

Chavel A. 1982. Contribuição para o estudo da evolução dos latossolos amarelos, distróficos, argilosos na borda do platô, na região de Manaus: mecanismos de gibbsitização. Acta Amaz., 11:227-245.

CNEN (Comissão Nacional de Energia Nuclear) (Ed.) 1988. Diretrizes básicas de radioproteção. CNEN, Rio de Janeiro, Resolução 12/88, $129 \mathrm{p}$.

Costa A.M.R., Waichman A., Santos E.E.A. 2003. Uso da água subterrânea na área urbana de Manaus. In: ABRH, Simp. Rec. Híd. Amazônia, 1, Anais, CD-ROM.

Cowart J.B. \& Osmond J.K. 1980. Uranium isotopes in groundwater as a prospecting technique. Colorado, U.S.Dept.of Energy, 112 pp.

Damião R.N., Souza M.M., Medeiros M.F. 1972. Projeto argila: Manaus. DNPM/CPRM, Manaus, 65 p.

Forti M.C. \& Moreira-Nordemann L.M. 1991. Rainwater and throughfall chemistry in a "terra firme" rain forest: Central Amazonia. $J$ Geophys. Res., 96:7415-7421.

Garrels R.M. (Ed.) 1960. Mineral equilibria. Harper \& Brothers, New York. 254 pp.

Golterman H., Clymo R.S., Ohmstad M.A.M. (Eds.) 1978. Methods for physical \& chemical analysis offreshwater. Blackwell Scientific $\mathrm{Pu}-$ blications, Oxford, v. 8, 213 pp.

Gomes F.V.M. 1978. Aplicação dos isótopos de urânio como traçadores de água subterrânea do Bambuí-BA. Dissertação de Mestrado, Universidade Federal da Bahia, $69 \mathrm{p}$.

Hem J.D. 1959. Study and interpretation of the chemical characteristics of natural water. U.S.G.S. Water Supply Paper, 1473:1-269.

IBGE (Instituto Brasileiro de Geografia e Estatística) 2002. Disponível em: http://www.sidra.ibge.gov.br/cidadesat/ufs/am.html. Acesso em: 16 de maio de 2002.

Ivanovich M., Fröhlich K., Hendry M.J. 1991. Uranium-series radionuclides in fluids and solids, Milk River aquifer, Alberta, Canada. Appl. Geochem., 6:405-418.

Krauskopf K.B. (Ed.) 1972. Introdução à geoquímica. Polígono, São Paulo, v. 2, 311 pp.

Lourenço R.S., Montalvão R.M.G., Pinheiro S.S., Fernandes P.E.C.A., Pereira E.R., Fernandes C.A.C., Teixeira W. 1978. Geologia. DNPM, Brasília, Projeto RADAMBRASIL, v. 18, p. 29-164.

Petri S., Fúlfaro V.J. (Eds.) 1988. Geologia do Brasil: Fanerozóico. EDUSP, São Paulo, v. 9, 631 p.

Piper A.M. 1944. A graphic procedure in the geochemical interpretation of water-analyses. Trans.Amer.Geophys.Union, 25:914-928.

Prance G.T., Lovejoy T.E. (Eds.) 1985. Amazonia: key environments. Pergamon Press, Oxford, p. 4.

Rebouças A.C. (Ed.) 1997. Panorama da degradação do ar, da água doce e da terra no Brasil. : IEA/USP, São Paulo, 150 p.

Santos U.M. \& Ribeiro M.N.G. 1988. A hidroquímica do rio SolimõesAmazonas. Acta Amaz., 18:145-172.

Santos A., Ribeiro M.N.G., Ribeiro J.S., Bringel S.R.B. 1981. Hidroquímica da Amazônia Central III. Química de água de lavagem da floresta no ecossistema Campina Amazônia (Streamflow). Acta Amaz., 11: 335-346.

Sawyer C.N. \& McCarty P.L. (Eds.) 1967. Chemistry for sanitary engineers. McGraw-Hill, New York, 518 pp.

Schoeller H. (Ed.) 1962. Les eaux souterraines. Masson \& Cie, Paris, $642 \mathrm{p}$.

Silva M.L. 2001. Características das águas subterrâneas numa faixa norte-sul na cidade de Manaus (AM). Rev. Esc. de Minas, 54:115-120.

Souza M.M. 1994. Dois poços tubulares anômalos em Manaus-AM. In: ABAS, Congr. Bras. Águas Sub., 8, Anais, p. 323-328.

Strickland J.D.H., Parsons T.R. 1968. A manual of sea water analysis. Bull. Fish Res. Bd. Can., 125:1-185.

Tancredi A.C.F.S. 1996. Recursos hídricos subterrâneos de Santarém: fundamentos para uso e proteção. Tese de Doutorado, Universidade Federal do Pará, $146 \mathrm{p}$.

Tancredi A.C.F.S., Lobato J.R.B., Serra V.H. 1987. Interpretação hidrogeoquímica das águas subterrâneas da ilha de Marajó. Acta Amaz., 16/17:293-316.

WHO (World Health Organization) 2005. Disponível em: http://www. who.int/mediacentrelfactsheets/fs257/en/print.html. Acesso em 11 de fevereiro de 2005 .

Manuscrito A1626 Aprovado em 26 de junho de 2006 